\title{
SILENT DISSECTION OF THE AORTA
}

\author{
BY \\ JENNER HOSKIN AND FRANCES GARDNER
}

From the Cardiological Department of the Royal Free Hospital

Received March 27, 1946

Dissecting aneurysm of the aorta has been known as a pathological entity for over a century (Maunoir, 1802); it was first diagnosed during life by Swaine (1856), and a full account of its clinical and pathological features was given by Peacock in 1863 . Even so, until recently only thirteen accurate ante-mortem diagnoses had been reported (Glendy et al., 1937). Failure to diagnose the condition has been mainly due to its relative infrequency and to consequent lack of clinical suspicion. In a large series, Shennan (1934) reported one dissecting aneurysm in every 175 autopsies; Reich (1944) reported the average incidence as one in 380 autopsies, while in our own hospital it has been found only twice in the 900 autopsies performed during the last six years. In the last decade, however, clinicians have become increasingly aware of the condition and a further 84 cases, accurately diagnosed during life, have been reported.

Although about 80 per cent of patients die within the first few days of dissection, accurate diagnosis is important because, in a small number, life and moderate health may be sustained for some years with appropriate supervision. The classical picture of dissecting aneurysm has been repeatedly described (Peacock, 1863; Gager, 1926; and White et al., 1935). The sudden onset of severe and prostrating pain, widely distributed throughout the body, together with evidence of interference with the blood flow in vessels arising from the diseased aorta, the appearance of an aortic diastolic murmur and a history of long-standing hypertension, form a syndrome which is not difficult to recognize once its significance is appreciated. Rare cases had, however, been reported where pain was absent and yet a recent or healed dissection was found at autopsy. These silent dissections are generally limited in extent, and it is not surprising that, in the absence of the characteristic pain, they are rarely suspected during life.

We report the following case because we have evidence of a silent dissection of the aorta. It was possible to make the diagnosis during life because the patient suffered a second attack characterized by the classical features of dissecting aneurysm. We believe this case to be of interest because the patient survived a second dissection of his aorta for over eighteen months, and because his illness was complicated by paroxysmal auricular flutter.

\section{CASE REPORT}

The patient, a cinema agent of 56, was first seen by us in October 1942. He had been breathless on exertion for two years, but recently had grown so much worse that a walk of only a few yards would cause him severe distress. During these two years he had had attacks of palpitation ; these might come on at any time and usually lasted a few hours. On questioning, he admitted to occasional substernal discomfort but at no time had he had any severe præcordial pain. Four years earlier he had been treated by rest in bed for obesity and hypertension.

Examination showed an obese Hebrew with cyanosis; he was so breathless that the slightest exertion caused him real distress. The pulse rate was 140 a minute, the rhythm irregular, and the blood pressure 180/130 in both arms. The heart was enlarged; there was a triple rhythm and a harsh systolic murmur at the apex and a ringing second sound in the aortic area. There was some congestion at the right lung base.

$\mathrm{X}$-ray examination of the chest revealed an enlarged heart and an enormously dilated and 


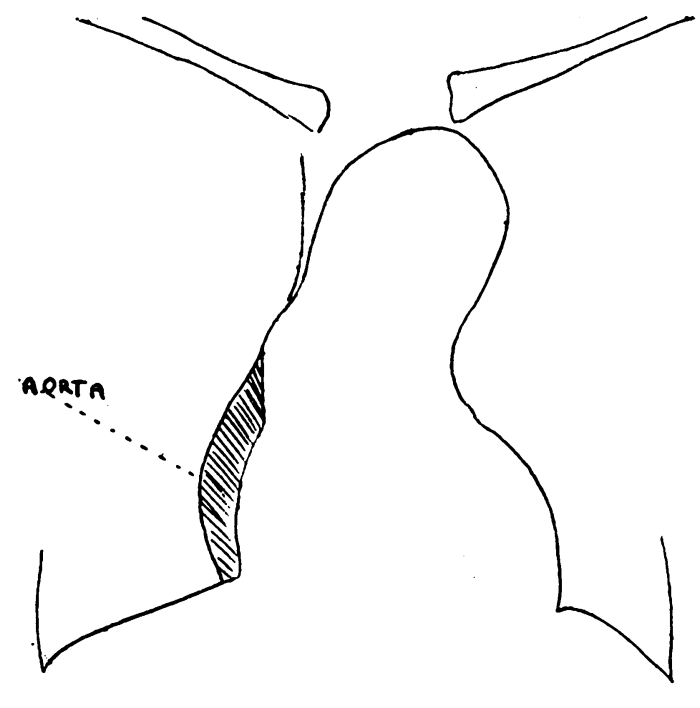

A

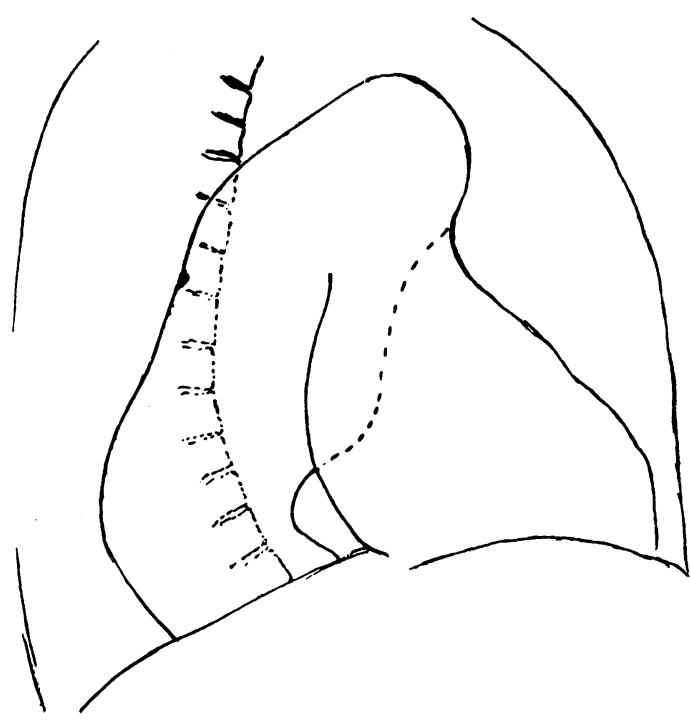

B

FIG. 1.-Orthodiagrams. 16/10/42.

(A) Showing dilated and tortuous aorta.

(B) Right (I) oblique position. The extent of the aortic enlargement can be clearly seen.

tortuous aorta (Fig. 1 and 2, A). The latter was seen more clearly on screening, when the lower thoracic aorta could be recognized lying behind and extending to the right of the right border of the heart (Fig. 1). The cardiogram showed irregular $2: 1$ and $3: 1$ auricular flutter (Fig. 3). The Wassermann and Kahn reactions were negative.

He was admitted to hospital and given digoxin, $0.25 \mathrm{mg}$. six-hourly by mouth. Normal rhythm was restored on the fourth day of treatment and there was sinus rhythm with depression of S-T II and III, compatible with digitalis therapy (Fig. 3, B). A diagnosis of atherosclerosis of the aorta associated with long-standing hypertension was made.

Thereafter he improved rapidly; the pulmonary congestion cleared and, when discharged three weeks later, he was no longer breathless when up and about. On discharge, quinidine sulphate 9 grains $(0 \cdot 6 \mathrm{~g}$.) daily was prescribed, and with this treatment the improvement was maintained during the next few months. He was able to look after his own home but he did not return to work; the heart rhythm remained normal and the blood pressure was maintained at about 175/120.

In March 1943, while at some dog races, he was seized with an agonizing pain in the chest and left arm. He lost consciousness for about half an hour, and after recovery complained that the left arm felt numb and useless. He was taken to a hospital nearby, where, on admission, the left hand was found to be cold and limp though movements at the shoulder were preserved. The state of the radial pulse was not recorded. Two hours later a detailed examination was made; the left hand was now warm and perfectly normal. While in hospital the cardiovascular findings were as follows: pulse 74-130, sometimes irregular; B.P. 110/90; heart enlarged to the left with double aortic murmurs; no congestive failure; sinus rhythm with a rate of 74 a minute. He was discharged after eight weeks.

We saw him two months later. During this time he had been without quinidine and had noticed a return of the palpitation. On examination, the pulse was 140 a minute and regular, but by contrast with our earlier observations the blood pressure in the right arm was now 110/90 and in the left arm 110/100, while in the aortic area the heart sounds were completely replaced by to and fro murmurs. There was no pulmonary congestion or peripheral œdema. There was $2: 1$ auricular flutter; X-rays of the chest showed slight increase in the diameter of the lower thoracic aorta but no other significant change (Fig. 2, B and C). It was at this time that we realized that our original diagnosis had been incomplete; the man had a dissecting aneurysm and the recent episode was a second dissection. He was readmitted and again normal rhythm was restored after a few days' treatment with digitalis. Quinidine 


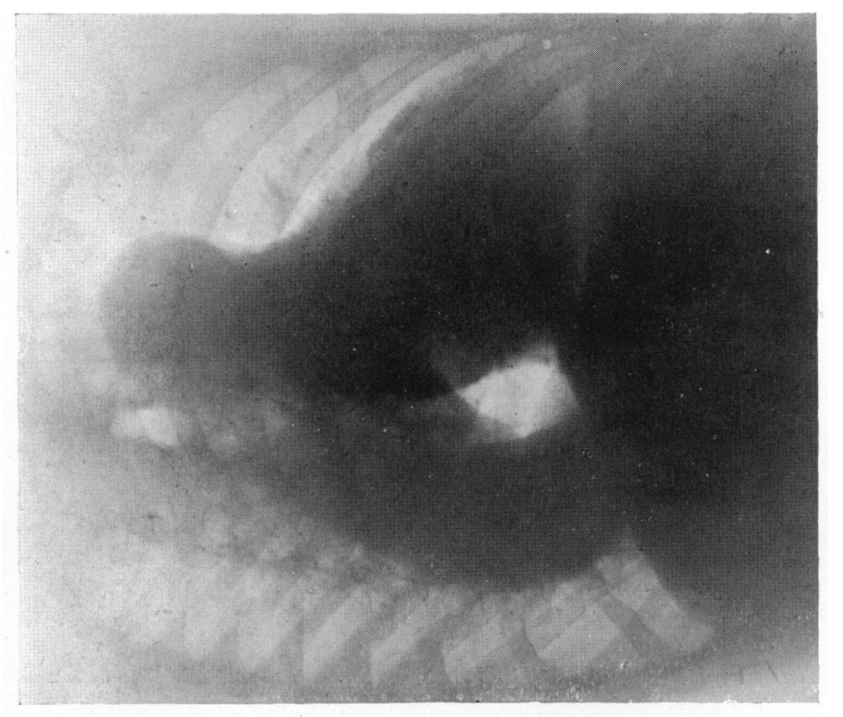

U
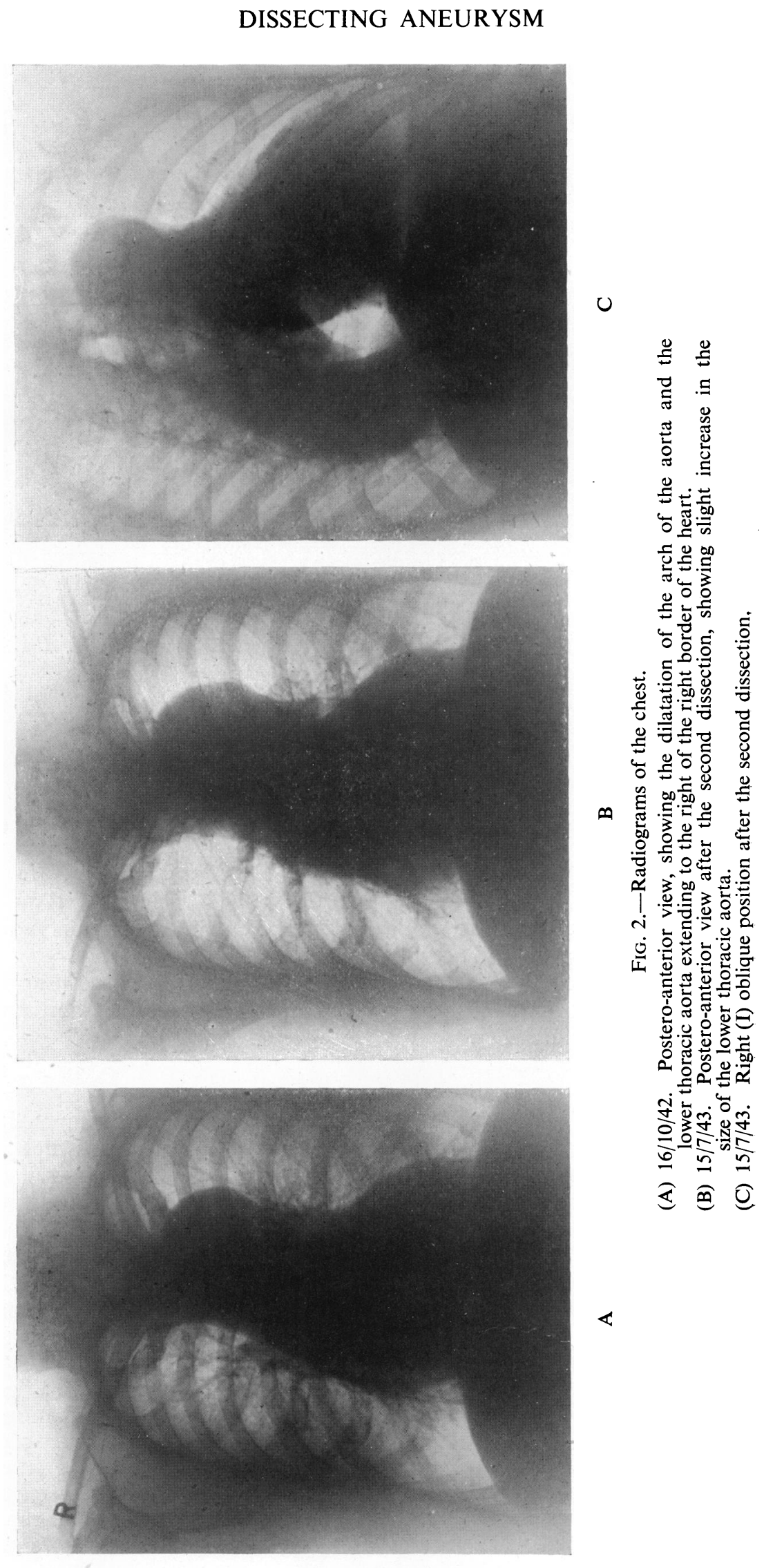
therapy was reinstituted and subsequent cardiograms showed a sinus rhythm with low voltage T waves (Fig. 3, C).

He was discharged after two weeks, but from this time could only lead a semi-invalid life. He was often severely breathless and from time to time complained of a "boring" pain in the back of the chest. The physical signs and blood pressure remained essentially unchanged. In July 1944, early congestive cardiac failure developed and he was readmitted for a few weeks. He improved slightly, but after discharge the signs of failure steadily increased. In the evening

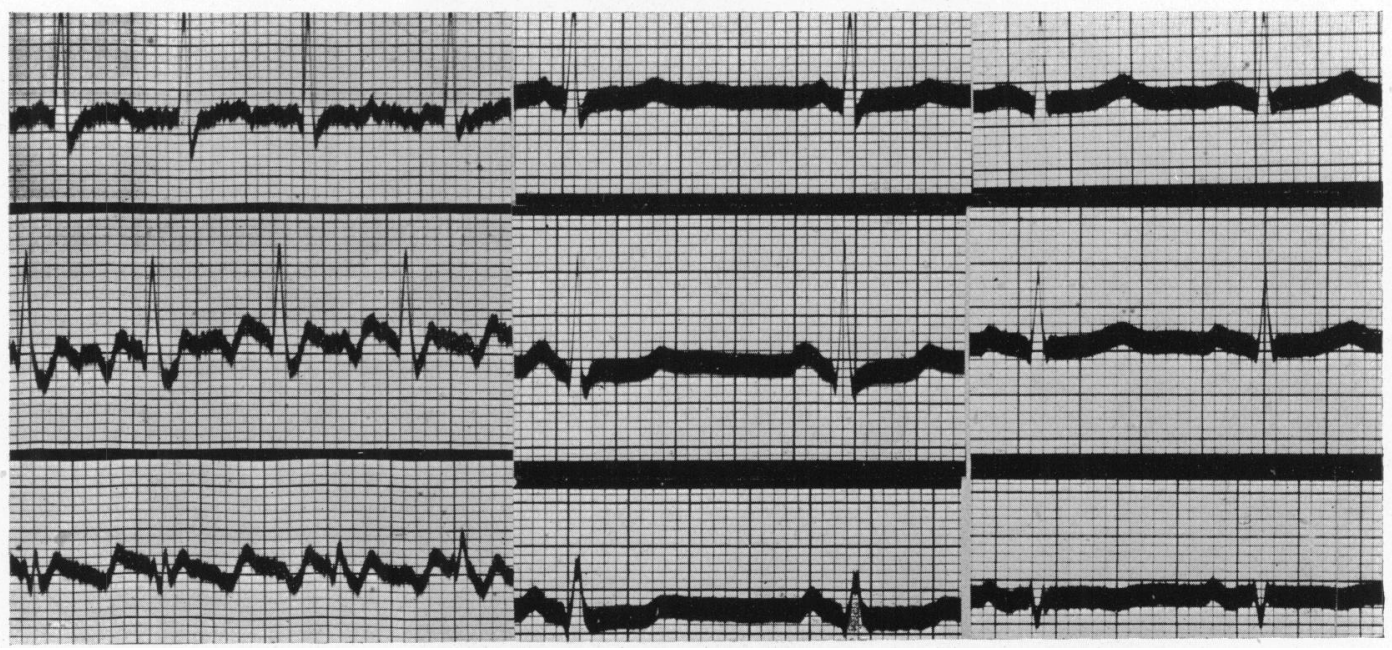

A

B

C

Fig. 3.-Electrocardiograms. Reduced to nine-tenths.

(A) 5/10/42. Showing $2: 1$ and $3: 1$ auricular flutter.

(B) 16/10/42. Sinus rhythm with slight depression of S-T I and S-T II compatible with digitalis therapy.

(C) 16/7/43. Sinus rhythm with low voltage $\mathrm{T}$ waves and slight inversion of $\mathrm{T}$ III.

of 20/12/44, after unusual exertion, he suddenly developed a very severe continuous pain in the back; it regressed to some extent, but a few hours later he died suddenly.

By the courtesy of the coroner for Westminster, we were able to attend the post-mortem examination. There was a partially healed dissecting aneurysm of the aorta, which had ruptured into the right pleural cavity.

\section{Post-mortem findings}

The heart was enlarged and the walls of the left ventricle were hypertrophied; the heart valves and the coronary arteries were healthy. In the aorta there was an elliptical opening in the intima $5 \mathrm{~cm}$. above the aortic valves extending two-thirds of the way round the right and posterior aspects of the vessel. This orifice led backwards towards the heart into a large sac, filled with organized thrombus and lying in front of the superior vena cava and the right auricle. Viewed from the auricular aspect the sac was bulging into the cavity of the right auricle in front of the superior eaval opening. From the elliptical tear the dissection wound spirally upwards in front of the ascending arch of the aorta, to reach the posterior aspect of the descending part of the arch, and in so doing the origins of the great vessels arising from the arch were dissected up 2-3 cm. The spiral direction of the dissection continued, the aneurysm lying on the posterior and the right aspects of the thoracic aorta, and it had ruptured back into the abdominal aorta, which was atheromatous, just above the bifurcation.

Throughout, the dissection occupied two-thirds of the circumference of the aorta, the true aorta appearing as a narrow tube attached to the larger dissecting aneurysm. Just above the diaphragm the aneurysm formed a saccular dilatation extending into the right pleural cavity. In this sac there was a longitudinal rent, $3 \mathrm{~cm}$. in length, where the external rupture which caused his death had occurred. The walls of the aneurysm were covered with a pearly white 
tissue resembling endothelium, with here and there partially organized adherent thrombi. The other organs showed no significant changes.

\section{Discussion}

The radiological appearance of the aorta remained essentially unchanged during the period this patient was under observation, and it is on this evidence that the diagnosis of silent dissecting aneurysm was made. The classical features of aortic dissection were only present during and after the second attack, and it seems likely that on this occasion the great vessels arising from the arch of the aorta became involved in the dissection, for the abnormal blood pressure readings found subsequently were evidence of new and permanent interference to the blood flow in the upper limbs.

The significance of the cardiac arrythmia found when this man was first seen is not entirely clear, but its presence supports the view that he had at that time a dissecting aneurysm. Abnormal heart rhythm has not often been reported in aortic dissection, probably because the common early fatal termination precludes cardiographic studies. In an extensive search we have found only one other report of auricular flutter associated with dissecting aneurysm (Mote and Carr, 1942), and other arrythmias are also rare. The saccular dilatation at the base of this patient's aorta encroached on the region of the sinus node and must have interfered with the mechanics of the right auricle. We therefore think the aneurysm was responsible for the auricular flutter, though, if this was so, it is remarkable, in view of the gross anatomical disturbance in this area, that digitalis and quinidine were able to control the abnormal rhythm.

Painless dissections of the aorta are rare episodes in a rare disease. In most of the reported cases the aneurysms have been limited in extent or they have failed to involve any of the great vessels arising from the arch of the aorta (Wedd and Thomas, 1932; Weiss, 1940; and Reich 1944). Sometimes the dissection has occurred during sleep and unconsciousness has supervened so rapidly that no complaint of pain could be made (Jessiman, 1939). In our case the original dissection was unusually extensive; it had probably involved the ascending aorta and from the X-ray appearances it is clear that the arch and the whole thoracic aorta were also affected. The absence of any history of anginal pain and the presence of hypertension in the arm suggest that this dissection had caused no interference with the blood flow in the coronary arteries or the great vessels arising from the aortic arch.

The pain of dissecting aneurysm has been ascribed to rapid distension of the adventitial tissues of the aorta by the effused blood and it has been thought that it may be absent if the dissection takes place slowly. In many cases, however, the pain, though severe, is limited to one arm or to both lower extremities, and in a few instances it has been indistinguishable from that of coronary thrombosis (Wainwright, 1944). Post-mortem examination in these cases has shown that the main limb vessels or the coronary arteries respectively have been involved in the aortic dissection. It is probable, therefore, that ischæmia is partially responsible for the pain and that in those rare cases where the coronary blood flow and the blood supply to the limbs is unimpaired, pain may be absent or inconsiderable.

For the majority of patients with dissecting aneurysm of the aorta no medical treatment can alter the fatal outcome. In a small number where, as in the case we have described, rupture back into the general circulation has taken place, complete rest in bed may relieve strain on the aneurysm wall and promote healing of the dissection. Subsequent management along the lines adopted for cardiac cripples does provide some hope of a return to partial activity.

\section{SUMMARY}

A case of recurrent dissection of the aorta with auricular flutter is described.

The first dissection was silent and was survived for over two years; the second presented the characteristic syndrome, and the patient died eighteen months later.

The cause of pain in dissecting aneurysm is discussed.

Gager, L. T. (1928). Ann. intern. Med., 2, 658.

\section{REFERENCES}

Glendy, R. E., Castleman, B., and White, P. D. (1937). Amer. Heart J., 13, 129.

Jessiman, J. B. (1939). Practitioner, 143, 643. 
Maunoir, J. P. (1802). Memoirs physiologique et practiques sur l'aneurisme et ligature des artères, Geneva Mote, C. D., and Carr, J. L. (1942). Amer. Heart J., 24, 69.

Peacock, T. B. (1863). Trans. Path. Soc. Lond., 14, 87.

Reich, N. E. (1944). Clinics, 3, 2, 346.

Shennan, T. (1934). Medical Research Council Spec. Series, 193.

Swaine, W. E. (1856). Trans. Path. Soc. Lond., 7, 106.

Wainwright, C. (1944). Bull. Johns Hopkins Hosp., 75, 81.

Wedd, A. M., and Thomas, W. S. (1931). Clifton Med. Bull., 17, 154.

Weiss, S., Kinney, T., and Maher, M. (1940). Amer. J. med. Sc., $200,192$.

White, P., Badger, T. L., and Castleman, B. (1933). J. Amer. med. Ass., 103, 1135. 